\title{
Experimental Research on Electrochemical Machining of an Arc-Shaped Slot Array
}

\author{
Feng Wang, Jianshe Zhao ${ }^{*}$, Dingming Liu, Yantao Fan, Zongjun Tian \\ College of Mechanical and Electrical Engineering, Nanjing University of Aeronautics and \\ Astronautics, Nanjing, 210016, China \\ *E-mail: zhaojs@ nuaa.edu.cn
}

doi; $10.20964 / 2018.10 .12$

Received: 6 June 2018 / Accepted: 26 July 2018 / Published: 1 September 2018

\begin{abstract}
Slot array structure is widely used in the aerospace industry, precision molds, instrumentation and other fields. Electrochemical machining has a unique advantage in the fabrication of slot arrays. However, there are still problems for electrochemical machining slot arrays with complex shapes, such as poor stability, low forming accuracy and difficult processing. To improve the processing ability of arc-shaped slot arrays, the influence of electrolyte flow pattern and pressure on flow field stability in a closed channel was studied with a computational fluid dynamics simulation, and the flow pattern and pressure parameters were optimized. Moreover, comparative experiments of continuous-feed electrochemical machining mode and low-frequency oscillation assisted electrochemical machining mode were carried out based on a self-developed oscillation apparatus. The influence of auxiliary oscillation motion on the processing stability frequency, average slot width, and slot slope was analyzed, and an arc-shaped slot array with a slot width of $0.244 \pm 0.01 \mathrm{~mm}$ and high accuracy in shape and dimension was fabricated on a rotary workpiece.
\end{abstract}

Keywords: Arc-shaped slot array; Electrochemical machining; Low-frequency oscillation; Reverse flow; Computational fluid dynamics simulation

\section{$\underline{\text { FULL TEXT }}$}

(C) 2018 The Authors. Published by ESG (www.electrochemsci.org). This article is an open access article distributed under the terms and conditions of the Creative Commons Attribution license (http://creativecommons.org/licenses/by/4.0/). 